\title{
Competencies of a Physical Culture Specialist Professional-Motor Activity
}

\author{
Olga Aftimichuk \\ State University of Physical Education and Sports \\ of the Republic Moldova, Chisinau \\ aftolig@gmail.com
}

\author{
Varvara Poleacova \\ State University of Physical Education and Sports of the \\ Republic Moldova, Chisinau \\ justwakooo@gmail.com
}

\begin{abstract}
Within the framework of training a physical culture specialist problem, the research is professional activity. A special place in its structure is occupied by motor component. In this aspect, in our opinion, the psychomotor competencies necessary for the teacher in the field of physical culture are poorly understood. Here it takes place to talk about the motor competencies of future teachers/trainers, consisting of performing physical exercises technique by a physical culture teacher or the motor elements of competitive exercises by the trainer. The correct demonstration of exercises determines the effectiveness of the educational process. And since the demonstration of exercises to students requires great physical strength, flexibility, speed reaction. A physical education specialist needs to have a special degree in psychomotor abilities/competencies. Establishing the place of psychomotor competencies in the professional activity of a physical culture specialist is the research purpose. The theoretical and praxeological researches of the professional mastery problem formation in students made it possible to determine four categories of the competences that make up the professional activity of a specialist in physical culture: specialmotor abilities (power abilities, flexibility, rapidity, endurance), specialized perceptions (feelings of rhythm, tempo, time, balance, space, object, partner, rival), reaction (moving object, sound, light), coordination abilities (motor coordination, auditory-motor, visual-motor, speech-motor, integrative/auditory-speech-visual-motor). The realization of research involves implementation of a competence approach ideas. They inherent the transformation of the emphasis in the content of educational programs of higher professional education with the teacher / discipline content to the student / expected results of education.
\end{abstract}

Keywords-professional training; psychomotorics; physical culture specialist.

\section{INTRODUCTION}

For the first time, the term "competence" was entrenched in linguistics thanks to the theory of the American linguist Noam Chomsky, the main idea of which is the existence of a person's linguistic ability (competence), presented in the form of special mental models and certain mental representations reflecting language knowledge. N. Chomsky noted (Chomsky, 1965, p. 4): “... we make a fundamental difference between competence (author: competence knowledge of the language) and performance (author: performance - use of the language in speech activity). Only in the idealized case ... performance is a direct reflection of the competence". At the same time, in the work of the American psychologist Robert Winthrop White "Motivation reconsidered: the concept of competence" (White, 1959), the category of competence is represented by personal components, including motivation.

At the same time, David Clarence McClelland is considered to be the founder of the competence theory. In his article "Testing for Competence Rather Than Intelligence" (McClelland, 1973) published by him in 1973, the researcher was against the academic tests to determine abilities and knowledge of the subject and proposed to test competencies, by which he understood the basic, personal characteristics that determine professional competence.

Later, in 1982, in the work "The competent manager: a model for effective performance" (Boyatzis, 1982), Richard Eleftherios Boyatzis gave a detailed definition of competence as the fundamental personal characteristic of a particular specialty/profession employee, assuming the effectiveness of his duties. He singled out the so-called threshold (significant, but not leading to efficiency) and differentiating (determining effectiveness) competencies. Of the 19 most common competencies, 12 were identified to scientists as differentiating competences and 7 as threshold ones.

On the European continent, the English psychologist John Raven, in his work "Competence in Modern Society" (Raven, 1997), presents competence as a phenomenon consisting of a large number of components, some of them are relatively independent, others belong to the cognitive sphere, and the third ones to emotional. All components, according to the author, can replace each other for the purpose of effective behavior. But, at the same time, J. Raven emphasizes that "types of competence" refer to "motivated abilities" (Raven, 2002, p. 258).

\section{LITERATURE REVIEW}

The continuation of the competence development in this aspect can be observed by N.V. Kuzmina (Kuzmina, 1990), where, on the basis of pedagogical activity, it is considered as a "personality trait". According to N.V. Kuzmina, 
professional and pedagogical competence includes five elements/types of competence (Kuzmina, 1990, p. 90):

1. "Special and professional competence in the field of the taught discipline.

2. Methodological competence in the field of knowledge and skills forming methods in students.

3. Socio-psychological competence in the field of communication processes.

4. Differential psychological competence in the field of motives, abilities, guiding the students.

5. Self-psychological competence in the field of advantages and disadvantages of one's own activity and personality".

A.K. Markova identifies special, social, personal and individual types of professional competence (Markova, 1996). According to L.M. Mitina, the concept of "pedagogical competence" includes "knowledge, skills, abilities, as well as methods and techniques for their implementation in activities, communication, development (self-development) of an individual" (Mitina, 1998, p. 46), which, in turn, implies the allocation of its activity and communication components. There are noteworthy developments of I.A. Zimnyaya (Zimnyaya, 2003), in which the author proposes to consider professional activity in three perspectives. The first is represented by the personal characteristic of the worker; the second is his competence, implying special knowledge and skills; the third is the ability to establish interpersonal and conventional relationships in communication.

As we see, in the presented works the concept of "competence" is presented both as personality professionalism and as well its component.

In the same vein, professor Yu.G. Tatur (Tatur, 2004) considers competency. The given category is presented by him as an integral property of a personality, characterizing its aspiration and ability to realize its potential (knowledge, skills, experience, personal qualities, etc.) for successful activity in a certain area, as well as awareness of its social significance and personal responsibility for the result of this activity, the need for its continuous improvement.

The presented position is traced in the content of educational programs of higher vocational education. The peculiarity of them lies in the implementation of the competence-based approach ideas. It is inherent in the transformation of emphasis from the teacher/content of the discipline to the student/expected results of education. Designing basic educational programs that implement state educational standards for higher professional education implies taking into account the structure of the concept "competence" adopted in the common European project "TUNING". According to it, the competence includes (Universities' contribution to the Bologna Process, 2008):
- "knowledge and understanding" (knowledge of the academic field, ability to know and understand)

- "knowledge how to act" (practical and operational application of knowledge to a specific situation)

- "knowledge of how to be" (values that are an integral part of perception and life with others in a social context).

Meanwhile the learning outcomes are planned in the following groups: knowledge and understanding (group A), intellectual skills (group B), practical skills (group C), transferable skills (group D).

Based on the taxonomy of Benjamin Samuel Bloom (Bloom, 1956), consideration of the education result components is assumed in three areas: cognitive, affective and psychomotor. B.S. Bloom proposed to organize the cognitive/learning sphere in the form of a six-level hierarchical structure: knowledge; understanding; application; analysis; synthesis; score. The emotional sphere, in his understanding, covers "relations", "feelings", "values", without which the educational process cannot be carried out. Psychomotor sphere is represented by physical skills, involving the coordination of mental and muscular activity. It is associated with practical skills.

\section{RESEARCH METHODOLOGY}

The analysis of the presented publications determined the purpose of the work. It implied the establishment of psychomotor competencies place in the professional activity of a physical culture specialist.

The research used the theoretical investigation methods: abstract and axiomatic methods, analysis and synthesis, induction and deduction, idealization, simile and generalization.

Systematization of scientific and theoretical knowledge of the "competence" and "psycho-motorics" categories was carried out using abstract and axiomatic methods, as well as the method of idealization.

It has been analyzed and synthesized works in the field of psychology, pedagogy, physiology, as well as the researches of the authors, whose study is aimed at improving the professional activities of a physical culture specialist. The materials studied were subjected to an inductive-deductive method of research.

Through the methods of comparison and generalization, an analytical definition of the psychomotor competencies structure was implemented, as well as the identification of the psychomotor competences composition in the professional and educational activities of a physical culture specialist.

\section{RESUlTS AND DISCUSSION}

Any professional activity consists of a specific activities complex (Fig. 1): gnostic, constructive, designing, organizational and communicative (Kuzmina, 2002). To this 
number, O.V. Petunin (Petunin, 1980) and K.M. Motorin (Motorin, 1980) add a specific component for the physical activity, the motor component.

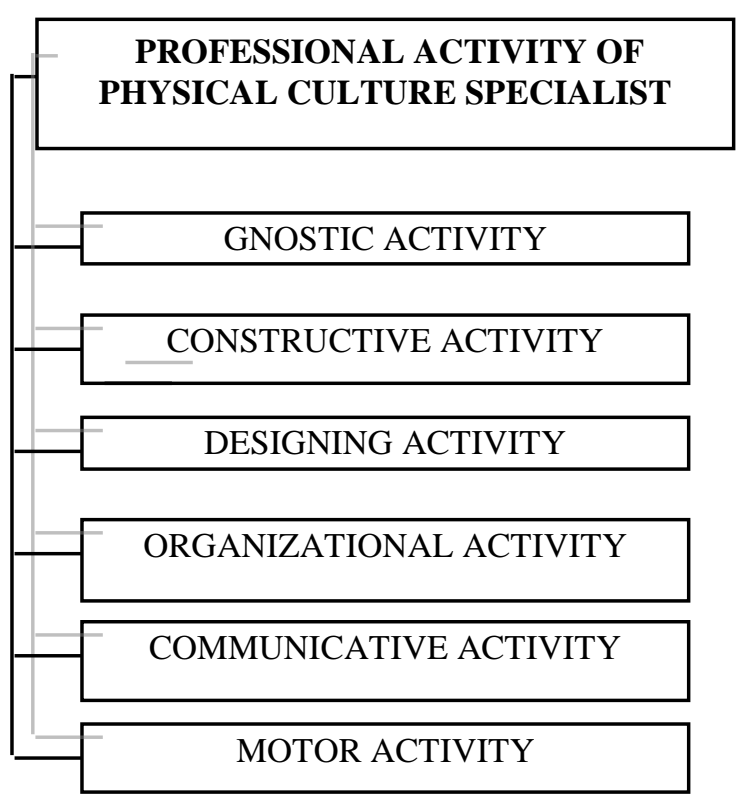

Fig. 1. The structure of the physical culture specialist professional activity

The last component focuses our attention, since it is the one who demonstrates the peculiarity of the physical culture specialist activity. And here there is a talk about the motor competencies of future teachers/coaches. They consist of physical exercises technique performed by a physical education teacher or the motor elements of competitive exercises by a trainer. The correct exercise demonstration determines the effectiveness of the educational process. And since the demonstration of exercises involved requires a great deal of physical strength, flexibility, quickness of reaction, a physical culture specialist needs to possess psychomotor abilities/competencies in a particular degree.

The term "psycho-motorics" was introduced by I.M. Sechenov in the process of describing the human psyche through his motor manifestations. By associating a person's motor function with the work of the higher parts of the central nervous system, he showed for the first time the mental conditioning of movements, represented by the ability to reflect objective information about motor behavior, control and manage their movements (Sechenov, 2009).

M.O. Gurevich and N.I. Ozeretsky (Gurevich \& Ozeretsky, 1930) consider the psycho-motorics as a link between conscious, automatic, and automated components of motor activity, manifested in an accurate, rapid, and consistent "adaptation" of the movement being studied. They identified four groups of psycho-motorics components (Table 1).
TABLE I. THE CONTENT OF PSYCHO-MOTORICS ACCORDING M.O. GUREVICH AND N.I. OZERETSKY

(GUREVICH \& OZERETSKY, 1930)

\begin{tabular}{|c|c|l|}
\hline № & GROUPS & \multicolumn{1}{c|}{ COMPONENTS } \\
\hline 1. & Extrapyramidal & $\begin{array}{l}\text { tone, change of innervation and denervation, pace, } \\
\text { rhythm, automatic movements (expressive and } \\
\text { protective), auxiliary movements }\end{array}$ \\
\hline 2. & Pyramidal & $\begin{array}{l}\text { force, energy of movements; distinctness of } \\
\text { execution }\end{array}$ \\
\hline 3. & Cerebellar & $\begin{array}{l}\text { cortical cerebellar components: balance, } \\
\text { proportionality of movements; coordination of } \\
\text { movements }\end{array}$ \\
\hline 4. & $\begin{array}{l}\text { the motor activity that determines the } \\
\text { environment, the change of environment and the } \\
\text { sequence of movements; ability to develop } \\
\text { formulas; the ability to preserve formulas } \\
\text { (engrams); ability to move simultaneously; } \\
\text { secondary automatisms }\end{array}$ \\
\hline
\end{tabular}

Based on the researches of physiologists such as P.K. Anokhin (Anokhin, 1975)(Theory of Functional Systems), N.A. Bernstein (Bernstein, 2004)(Teaching about the physiology of activity), A.P. Lurya (Lurya, 1974)(Theory of systemic dynamic brain localization of mental functions), a psychomotor can be represented as a multi-level dynamic self-regulating functional system determined by the integration activity of brain structures. And here the principle of the Dominant is traced, when the dominance of one system is replaced by the dominance of another depending on the change of actual behaviour. At the same time, as noted by Yu.I. Rodin, the state of psychomotor activity "is limited to homeostasis and rhythmically organized information, that is, socially developed ways of regulating motor behaviour, rules, ways, rituals, canons, prohibitions, etc.” (Rodin, 2011, p. 392).

In the same perspective one can consider the development of B.G. Ananyev (Ananyev, 1961), who identified four levels of psychomotor activity:

1 - the level of holistic activity, as a historically established system of programs, operations and means of society material and spiritual values production;

2 - the level of a separate act of activity (action);

3 - the level of macro-movements, of which actions are built;

4 - the level of micro-movements, of which macromovements are built.

N.E. Korenkova (Korenkova, 2005) empirically revealed the general structure of psychomotor activity that she presented in her 5-factor organization:

- excitability - lethargy;

- selection reaction rate;

- accuracy of movements;

- sensorimotor coordination;

- the speed of a simple reaction. 
At the same time, the author identified typological features of the psychomotor organization. They are reflected in four types of individual psychomotor profiles: fast, monotonous, accurate and impulsive.

In continuation of this, it is possible to present three main areas of psychomotor activity study according to E.P. Ilyin (Ilyin, 2003):

- propulsion system and its management;

- motor abilities (skills);

- motor (psychomotor) qualities.

As well as the unification of the psychomotor interpretation of K.K. Platonov (Platonov, 1972), E.P. Ilyin (Ilyin, 2003), V.P. Ozerov (Ozerov, 2002), defining it as the objectification of all forms of mental reflection, taking place in sensorimotor, ideomotor and emotional-motor reactions and acts, which reveals the role of muscle sensitivity in controlling movements in time and space, as well as its connection with visual and auditory sensations.

Nowadays, the psychomotor category is represented in almost all educational areas. It occupies a special place in the system of professional training in physical education and sport. All psychomotor classes presented are consistent with the activities of the teacher/trainer. From this point of view, all psychomotor competencies can be differentiated into the following groups, presented in Table 2.

TABLE II. CONTENT OF A PHYSICAL CULTURE SPECIALIST PSYCHOMOTOR COMPETENCE

\begin{tabular}{|c|l|l|}
\hline № & GROUPS & \multicolumn{1}{c|}{ CONTENTS } \\
\hline 1. & $\begin{array}{l}\text { Special motor } \\
\text { abilities }\end{array}$ & $\begin{array}{l}\text { power abilities, flexibility, speed, endurance } \\
\text { (Polevaya-Sekeryanu \& Aftimichuk, 2015; } \\
\text { Faur, Aftimichuk \& Danail, 2014) }\end{array}$ \\
\hline \multirow{2}{*}{$\begin{array}{l}\text { feelings of rhythm, pace, time, balance, space, } \\
\text { object/thing, partner, opponent (Aftimichuk, } \\
\text { 2015b; Evzhenko, 2013; Krayzhdan \& } \\
\text { Aftimichuk, 2015; Polevaya-Sekeryanu \& } \\
\text { Aftimichuk, 2015; Faur, Aftimichuk, \& Danail, } \\
\text { 2014) }\end{array}$} \\
\hline 3. & Reactions & $\begin{array}{l}\text { on a moving object/thing, sound, light } \\
\text { (Krayzhdan \& Aftimichuk, 2015; Polevaya- } \\
\text { Sekeryanu \& Aftimichuk, 2015) }\end{array}$ \\
\hline 4. & $\begin{array}{l}\text { motor coordination, auditory-motor, visual- } \\
\text { motor, speech-motor, integrative (auditory- } \\
\text { speech-visual-motor) (Aftimichuk, 2015a; } \\
\text { Aftimichuk, 2016; Polevaya-Sekeryanu \& } \\
\text { Aftimichuk, 2015; Faur, Aftimichuk \& Danail, } \\
\text { 2014; Gönczi-Raicu, Aftimichuk \& Danail, } \\
\text { 2014) }\end{array}$ \\
\hline
\end{tabular}

In order to clarify the value and significance of the didactic personnel psychomotor competencies, several pedagogical experiments were carried out on the basis of the State University of Physical Education and Sport of the Republic of Moldova and the Western University of Timisoara in Romania. The research results are presented in monographs (Polevaya-Sekeryanu \& Aftimichuk, 2015;
Faur, Aftimichuk \& Danail, 2014; Gönczi-Raicu, Aftimichuk \& Danail, 2014).

\section{CONCLUSIONS}

Introduction to the concept of education competence defines by itself a paradigm that addresses vocational training, where problems of a student/student's personality are considered. They define its integral property, characterize the desire and ability to realize its potential. At the same time, a personal attitude towards an activity/profession, aimed at solving a certain range of tasks/problems that are significant for it, implies a person's competence.

According to this paradigm, the educational standards of higher professional pedagogical education are based on the competence approach. It consists of the strengthening orientation towards the results of education as a systemforming component of the standard's construction.

Theoretical and praxeological researches about the formation of students' professional skills led us to the definition of four categories of psychomotor competencies that make up the professional activities of a physical culture specialist. The latter provision brings a broad perspective to further research in this aspect.

\section{References}

[1] Aftimichuk, O. Integrative coordination abilities of coaches in wellness types of gymnastics. Baltic Journal of Sport and Health Sciences, 2015a, 4(99), pp. 2-7.

[2] Aftimichuk, O. Theory and practice of rhythm in the professional training system for athletes and teaching staff. Journal: Pedagogic, Psychology, Medico-Biological Problems of Physical Training and Sports, 2015b, 9, pp. 69-74.

[3] Aftimichuk, O. Componential and structural content of integral didactic activity of physical education teacher. Journal: Sporto mokslas / Sport Science, 2016, 2(84), pp. 35-41.

[4] Ananyev, B.G. Theory of sensations. Leningrad: Leningrad University Press. 1961.

[5] Anokhin, P.K. Essays on the physiology of functional systems. Moscow: Medicine. 1975.

[6] Bernstein, N.A. Biomechanics and physiology of movements: Selected psychological works; 2nd ed. Moscow; Voronezh: MPSI: MODEK. 2004.

[7] Bloom, B.S. Taxonomy of educational objectives. The classification of educational goals: Handbook I, cognitive domain. New York: Longman, 1956, vol. 1.

[8] Boyatzis, R.E. The competent manager: a model for effective performance. New York: Wiley. 1982.

[9] Chomsky, N. Aspects of the Theory of Syntax. Cambridge, MA: MIT Press. 1965.

[10] Evzhenko, N. Significance of rhythm in the system of learning motor actions of young water polo players. Young is the sport of science of Ukraine. Issue 17: in 4 volumes. Lviv: Lviv State University of Physical Education, 2013, vol..1, pp. 62-66.

[11] Faur, M.-L., Aftimichuk, O., Danail, S. Ritmul activităţii motrice în sistemul pregătirii profesionale pedagogice a profesorului de educaţ̧ie fizică. Chişinău: Valinex. 2014.

[12] Gönczi-Raicu, M., Aftimichuk, O., Danail, S. Competenţe de coordonare complexă în cadrul activităţii didactice integrative a profesorilor de educaţie fizică. Chişinău: Valinex. 2014.

[13] Gurevich, M.O., Ozeretsky, N.I. Psychomotor activity. MoscowLeningrad: State medical publication, 1930, Part 1.

[14] Ilyin, E.P. Psychomotor organization of man: Textbook for universities. St. Petersburg: Peter. 2003. 
[28] Raven, J. Competence in modern society. Its Identification, Development and Release. Oxford, England: Oxford Psychologists Press, 1984; Revised Unionville, New York: Royal Fireworks Press. 1997.

[29] Raven, J. Competence in modern society. Identification, development and implementation. Moscow: Kogito Center. 2002.

[30] Rodin, Yu.I. Human psychomotor activity in the light of the systemic and evolutionary paradigms. Journal of Proceedings of Tula State University. The Humanitarian sciences, 2011, 3, pp. 389395.

[31] Sechenov, I.M. Reflexes of the brain. Moscow: Vira-M. 2009.

[32] Tatur, Yu.G. Competence-based approach in the description of results and the design of higher professional education standards. Materials for the second meeting of the methodological seminar. Author's version. Moscow: Research Center for Advanced Teaching Skills. 2004.

[33] Universities' contribution to the Bologna Process. An introduction: Tuning project; 2nd Edition. Bilbao: University of Deusto. 2008.

[34] White, R.W. Motivation reconsidered: The concept of competence. Psychological review, 1959, 66, pp. 297-333.

[35] Zimnyaya, I.A. Key competencies - a new paradigm of the result of education. Higher education today, 2003, 5, pp. 34-42.

[36] Aftimichuc O.E., Kuznetsova Z.M. The Importance of Rhythm in the System of Professional Pedagogical and Sport Training. Pedagogico-pshycological and medico-biological problems of physical culture and sports. 2015, 10(2), pp. 6-14. DOI: 10.14526/01_1111_04. 